eISSN: 2387-1555

DOI: http://dx.doi.org/10.14201/rea20209105124

\title{
EL PATRIMONIO WIXARIKA: HISTORIA, MEMORIA Y LUCHA POLÍTICA EN EL CONTEXTO DEL MULTICULTURALISMO ${ }^{1}$ Wixarika heritage: history, memory and political fight in the context of multiculturalism O patrimônio Wixarika: história, memória e luta política no contexto do multiculturalismo
}

\author{
María de la Concepción SÁNCHEZ DOMÍNGUEZ-GUILARTE \\ CIESAS-CIDIGLO México \\ 凶coquisdg@hotmail.com
}

Fecha de recepción: 9 de septiembre de 2019

Fecha de aceptación: 10 de enero de 2020

\begin{abstract}
Resumen: Si bien el multiculturalismo ha contribuido a un reconocimiento creciente de los derechos de los pueblos indígenas, la realidad es que faltan mecanismos para que dichos derechos puedan ejercerse. En este artículo se propone un análisis de esta situación desde un caso concreto, el de Wirikuta, lugar sagrado de los wixaritari, situado en el desierto de San Luis Potosí, en México. Es difícil, en términos positivistas, definir qué es el patrimonio biocultural de este grupo, ya que no se limita a aspectos culturales/naturales, sino que abarca todo un conjunto de prácticas, espacios comunitarios y, también, lugares sagrados ubicados lejos de sus comunidades de origen. Así, podemos observar los límites del enfoque multicultural a la hora de ejercer sus derechos, tanto en los aspectos legales como en las estrategias de lucha social, centrándonos en la enorme relevancia que juegan la memoria colectiva, el mito y la historia para la defensa de estos derechos. Por último, se propone trabajar desde una resignificación del concepto de patrimonio, que permita un ejercicio real de los derechos de los pueblos indígenas.
\end{abstract}

Palabras claves: patrimonio; indígenas; Wirikuta; multiculturalismo.

Abstract: Although multiculturalism has contributed to the recognition of the rights of indigenous peoples, the reality is that there is a lack of mechanisms for these rights to be exercised. This article proposes an analysis of this situation from a specific case, Wirikuta, a sacred site of the Wixaritari, located in the desert, in San Luis Potosí, Mexico. It is difficult, in positivist terms, to define what the biocultural heritage of this group is, since it is not limited to cultural / natural aspects, but covers a whole set of practices, community spaces and, also, sacred sites located far away from their communities. We can observe how de multiculturalism has limits when the indigenous people wants exercises their rights. We will focus on the enormous relevance that collective memory, myth and history has for the defense of these rights. Finally, it is proposed a resignification of the concept of biocultural heritage, which allows a real exercise of the rights to the indigenous peoples.

Key words: heritage; indigenous people; Wirikuta; multiculturalism.

Resumen: Embora o multiculturalismo tenha contribuído para um crescente reconhecimento dos direitos dos povos indígenas, a realidade é que faltam mecanismos para que esses direitos sejam exercidos. Este artigo propõe uma análise dessa situação a partir de um caso específico, o de Wirikuta, o local sagrado dos wixaritari, localizado no deserto de San Luis Potosí, no México. É difícil, em termos positivistas, definir qual é o patrimônio biocultural desse grupo, uma vez que não se limita a aspectos culturais / naturais, mas abrange todo um conjunto de práticas, espaços comunitários e, também, lugares sagrados localizados longe de suas comunidades. de origem. Assim, podemos observar os limites da abordagem multicultural no exercício de seus direitos, tanto nos aspectos legais quanto nas estratégias de luta social, enfocando a enorme relevância que a memória coletiva, o mito e a história desempenham na defesa desses direitos. Por fim, propõe-se trabalhar a partir de uma ressignificação do conceito de patrimônio, que permita um exercício real dos direitos dos povos indígenas.

Palavras-chave: patrimonio; indígena; Wirikuta; multiculturalismo.

${ }^{1}$ Este artículo fue elaborado en el marco del proyecto «La diáspora wixarika: expansión territorial, cambio y modernidad en las comunidades huicholas de Nayarit y Durango» (CONACYT-Ciencia Básica número 243126 


\section{Introducción}

Como bien se señala en la introducción de esta revista, existe una tensión entre la memoria indígena y los discursos históricos occidentales. La historia es una de los pilares que legitiman los Estados nación liberales, que desde el siglo XIX ha ido consolidándose como la unidad básica de la estructura internacional actual. Pero, entre los pueblos indígenas del mundo, la historia no juega necesariamente este papel, sino que presenta otras formas de hacer presente su pasado. Esta tensión entre la memoria indígena y la historia se refleja no solo en los discursos, sino también en las leyes y estructuras dominantes, que impiden a los grupos indígenas disponer de una autonomía real a la hora de gestionar sus territorios de acuerdo a su costumbre.

En este artículo, proponemos reflexionar acerca del término patrimonio, tal y como actualmente aparece reconocido en las legislaciones nacionales y los tratados internacionales, con el fin de observar qué papel puede jugar a la hora de proteger los derechos de los pueblos indígenas, en concreto, en el caso de los wixaritari. El interés por este concepto radica en la gran popularidad que ha alcanzado este término, que es utilizado muchas veces para defender aquello que las comunidades consideran que es suyo, de una forma muy vaga y genérica. Proviene de un concepto positivista, que refleja la concepción occidental de la idea de propiedad y herencia. Si bien, originalmente se centró en la protección de espacios monumentales, con el auge del multiculturalismo ha ido incluyendo un número casi ilimitado de rasgos «patrimonializables». Esta amplitud del término, pretende hacerlo más representativo de la diversidad del mundo.

Muchos grupos indígenas han decidido utilizar este concepto, e incluso promover acciones de patrimonialización, para defender tradiciones o espacios. No obstante, el concepto que tienen estos grupos sobre el patrimonio no necesariamente es el mismo que el que defienden las instituciones. El patrimonio se construye de cara al otro. Los grupos indígenas han adoptado una categoría occidental para decirnos: «esto es nuestro». La patrimonialización no ha sido necesaria hasta que han sentido que sus costumbres, sus tradiciones, sus espacios sagrados o su forma de vida estaban amenazadas (SÁNCHEZ DOMÍNGUEZ-GUILARTE, 2015). Esta forma de utilizar el patrimonio, se relaciona además con los contextos jurídicos nacionales e internacionales, y sobre todo, con el reconocimiento de los pueblos a ejercer su derecho de decidir sobre aquello que les afecta.

A pesar de las limitaciones del término, derivados precisamente de esta concepción positivista del mundo, el patrimonio contempla aspectos que han permitido generar puntos de articulación con las culturas indígenas. En primer lugar, reconoce las colectividades como sujeto, lo que no es tan frecuente en la legislación occidental. Además, esta amplitud cada vez mayor del término, permite una importante flexibilidad a la hora de definir qué es importante para cada pueblo. Por último, presenta de forma genérica un enlace entre el pasado, mítico o histórico, de un grupo, el presente (ejemplificado en el patrimonio) y el futuro, en el sentido de la permanencia de su costumbre. Este último aspecto es el que más nos interesa con respecto a este artículo ya que la concepción del pasado no es igual entre las sociedades positivistas, donde domina la historia, o un pueblo indígena, donde el mito se actualiza constantemente.

Junto con estos rasgos articuladores, hay otros que nos hablan de las contradicciones internas de las políticas patrimonializadores, tal y como se llevan a cabo en la actualidad. Así, estos reconocimientos tienen como principal objetivo la explotación turística de los mismos, es decir, hay una clara motivación económica para reconocer patrimonios. Además, las protecciones se refieren solamente a los aspectos más estéticos o superficiales, es decir, no consideran la protección y el ejercicio del derecho a decidir sobre recursos como el agua, los minerales o la tierra. Sólo se centran en la estética y la importancia histórica o biológica de dichos 
patrimonios (PRATS, 2011). Esto lleva a mayores contradicciones cuando hablamos de patrimonios complejos, donde no se responde a lógicas históricas, sino míticas, y donde las categorías de naturaleza y cultura no sirven para describir las realidades. Esto implica que las divisiones actuales de patrimonio, en natural y cultural, y este último en tangible o intangible, no proveen un marco adecuado para recoger la diversidad de pensamiento de los pueblos del mundo. Así, las instituciones nacionales e internacionales están optando por utilizar el adjetivo de biocultural, con el fin de dar considerar una mayor integralidad.

Este artículo tiene como objetivo analizar hasta qué punto el marco jurídico nacional e internacional, bajo el paradigma de la multiculturalidad, ha contribuido a la defensa del caso de Wirikuta, un lugar sagrado wixarika que se encuentra inmerso en una fuerte controversia, y donde intereses políticos, económicos y espirituales convergen. Se analizarán una serie de documentos legales, de declaraciones y noticias periodísticas, así como datos que proceden de trabajo de campo en la zona de Wirikuta y en la sierra, en comunidades wixaritari, entre los años 2011 y 2017.

Este caso permite observar hasta qué punto se han articulado estrategias comunes entre distintas comunidades y, por otro, cómo estas han resultado insuficientes para proteger y salvaguardar espacios tan complejos como un lugar sagrado, que superan por mucho las categorías tradicionales recogidas en las leyes y en los convenios internacionales, como la de patrimonio. Estas categorías tradicionales suelen priorizar los argumentos positivistas para justificar sus decisiones. Así, la historia, la estética y la naturaleza se convierten en los criterios principales para proteger patrimonios (PRATS, 2011). Pero hay otras comunidades donde la memoria y el mito tienen una mayor trascendencia en sus propias tradiciones. Considero que, a partir del análisis de este caso se pueden apuntar algunos aspectos para ir hacia un nuevo concepto de patrimonio de los pueblos, basado en el reconocimiento de su propia tradición, donde la memoria, el mito y la historia puedan convivir, sin presuponer que uno es más auténtico que el otro.

\section{El contexto jurídico bajo el multiculturalismo}

La tradición jurídica del continente americano es muy variada aunque, salvo quizás la excepción de Bolivia, procede mayoritariamente del positivismo. Esto se refleja también en el reconocimiento de los pueblos indígenas y sus derechos. En líneas generales, podemos destacar dos tipos de enfoques: aquellos que derivan de la tradición anglosajona, donde se establecen pactos concretos con los grupos indígenas para regular su situación ante la tierra y los recursos, cuyo ejemplo más conocido es el estadounidense, y las que tienen origen en las legislaciones de tradición latina, que desarrollan una amplia legislación indigenista en el plano constitucional, se responsabilizan por sus comunidades y se fijan ciertas reglas. En la actualidad, la tendencia de estas últimas legislaciones es la de contribuir a la supervivencia de las culturas y la protección de las tierras (BARIE, 2003:87). Dos son sus principales problemas: por un lado, la falta de mecanismos para que estas leyes sean efectivas y, por otro, la duda sobre si estás leyes son adecuadas para proteger realmente los derechos de los pueblos indígenas.

Desde finales de los años 60, la comunidad internacional empieza a discutir sobre derechos culturales y el reconocimiento de la diversidad. Dentro de las democracias liberales, que en estos momentos todavía siguen siendo el modelo ideal a nivel internacional, se consolida la idea de que los estados son espacios donde conviven diversas culturas y que se debe proveer de marcos jurídicos «neutrales» que de alguna forma permitan a dichas culturas pervivir. Los límites de este paradigma vienen dados por los derechos reconocidos por las democracias liberales. Así, consideramos el multiculturalismo como un paradigma propio de la tradición liberal que identifica 
una única naturaleza, y una gran diversidad de culturas que se apropian y relacionan con ella. En este sentido, retomo para esta definición la idea de VIVEIROS DE CASTRO (2013 [2002]) sobre multiculturalismo. Dentro de las democracias liberales, además, se considera que dichas culturas deben ser respetadas, siempre que se mantengan dentro de los marcos legales nacionales e internacionales aprobados y, en especial, del corpus internacional de Derechos Humanos.

El concepto de cultura que reconocen estas democracias liberales, entre las que se encuentra México, está muy ligado a las resoluciones adoptadas en la Conferencia Mundial sobre las Políticas Culturales, realizada en 1982 en este mismo país. En esta reunión, se resalta la importancia de la diversidad cultural y la igualdad de las culturas (UNESCO, 1982) promoviendo un concepto de cultura más plural y menos elitista, proveniente de la reflexión antropológica. Esta declaración, posteriormente se irá fortaleciendo con una serie de declaraciones con valor normativo en favor de esa diversidad, tales como la La Declaración sobre los Derechos de las Personas pertenecientes a Minorías Nacionales o Étnicas, Religiosas y Lingü̈sticas (ONU, 1992), donde se reconocen los derechos individuales de las personas, más no los colectivos. Posteriormente, en el año 2017 se aprueba la Declaración de los Derechos de los Pueblos Indigenas (ONU, 2007), misma que reconoce las condiciones especiales de dichos pueblos y que tiene su antecedente más directo en el Convenio 169 de la Organización Internacional del Trabajo (OIT, 1989), que sustituyó al 107 (OIT, 1957).

En este Convenio 169, referencia en casi todos los textos donde los pueblos indígenas reivindican sus derechos, se recomendó adoptar nuevas normas internacionales en la materia de derechos indígenas, con el fin de eliminar la orientación hacia la asimilación de las normas anteriores. Asimismo se reconocen «las aspiraciones de esos pueblos a asumir el control de sus propias instituciones y formas de vida y de su desarrollo económico y a mantener y fortalecer sus identidades lenguas y religiones, dentro del marco de los Estados en que viven. Se denuncia que, en muchos países, estos pueblos no gozan de sus derechos fundamentales y, por último, se recuerda la contribución de los pueblos indígenas y tribales a la diversidad cultura, a la armonía social y ecológica de la humanidad [...]» (OIT, 1989: preámbulo). Esta línea se ha profundizado posteriormente en numerosas resoluciones y recomendaciones emitidas por la propia $\mathrm{ONU}$ o sus agencias.

Esta tendencia internacional se ha visto reflejada en las constituciones de los países que cuentan con pueblos indígenas. En el caso mexicano, que es el que nos ocupa en este artículo, estas transformaciones comenzaron ya desde los 90, muchas de ellas en el marco de las conmemoraciones por la llegada de los europeos a América. No obstante, la reforma fundamental se llevó a cabo en el año 2003, cuando se cambia el artículo segundo de la Constitución para incluir a los pueblos indígenas como objeto de derecho y desglosar detalladamente sus derechos reconocidos por dicha norma. El mencionado artículo tiene un preámbulo donde define a los pueblos indígenas y su papel dentro del Estado mexicano y, además, reconoce su derecho a la libre determinación, dentro de «un marco constitucional de autonomía que asegure la unidad nacional». Posteriormente, en la primera parte, profundiza en los aspectos en los que las comunidades podrán ejercer esa libre determinación y, en consecuencia, autonomía: decidir sus formas internas de convivencia y organización social, económica, política y cultural, sistemas normativos, elección de autoridades, acceder a sus recursos y «preservar y enriquecer sus lenguas, conocimientos y todos los elementos que constituyan su cultura e identidad». Estos aspectos, tendrán como límites la constitución mexicana y sus leyes. 
En la segunda parte del artículo segundo, se convoca a las instituciones a promover la igualdad de oportunidades y eliminar la discriminación y para ello «se establecerán las instituciones y determinarán las políticas necesarias para garantizar la vigencia de los derechos de los indígenas y el desarrollo integral de sus pueblos y comunidades, las cuales deberán ser diseñadas y operadas juntamente con ellos».

Esta reforma fundamental de la constitución reconoce a los indígenas contemporáneos como parte sustancial de la nación. Por supuesto, esto debería tener implicaciones directas con el uso y disfrute de los pueblos indígenas de su territorio, así como otros elementos propios de un patrimonio biocultural, entendido en sentido amplio. Junto con este artículo segundo, el artículo cuarto, modificado en el 2009, garantiza el ejercicio de los derechos culturales a toda la población mexicana y, por último, en el año 2011, se modifica el artículo primero para garantizar el ejercicio de los Derechos Humanos «reconocidos en esta Constitución y en los tratados internacionales de los que el Estado Mexicano sea parte (...)». Esto pone al mismo nivel que la constitución los tratados internacionales de los que México es signatario, incluyendo algunos fundamentales para los derechos de los pueblos indígenas e incorpora formalmente la visión de derechos humanos en el país (Congreso de los Estados Unidos Mexicanos, 2019). Este reconocimiento de derechos, serán fundamentales para las reivindicaciones de los pueblos indígenas en México. La constitución mexicana refleja el positivismo jurídico (CRUZ, 2014: 42-43) multicultural y, si bien reconoce a los pueblos indígenas y su aportación a la nación, prevalecen las normas jurídicas liberales ante la tradición propia.

Este contexto legal es especialmente pertinente para el caso del grupo indígena wixarika y su defensa de la tierra sagrada Wirikuta. Así, observamos como la tradición indígena wixarika, donde la costumbre propia y el papel predominante del mito son esenciales para la comprensión de su territorio, encuentra serias dificultades para hacer valer sus derechos ante el positivismo historicista imperante en la tradición del estado mexicano y los grupos mestizos con los que comparte patrimonios. Desde la época colonial, los wixaritari han demostrado un gran pragmatismo para generar alianzas con instituciones mestizas, a la vez que mantenían sus propias formas de vida.

Así, para ellos no suponía ningún conflicto, por ejemplo, participar dentro de las milicias indígenas del rey, a la vez que promovían rebeliones en contra de los propios franciscanos de las misiones. Los huicholes son un pueblo complejo, heterogéneo, con discrepancias entre ellos mismos, que conoce los mecanismos legales del Estado y los utiliza cuando considera pertinente. Cuando ha sido necesario, han acudido a tribunales mexicanos para reivindicar sus territorios, y a instancias internacionales para visibilizar algunos de sus conflictos. Además, han tejido redes con movimientos sociales mestizos, que les han permitido ejercer una mayor presión social a la hora de defender lo que ellos consideran que es suyo.

A pesar de que la lucha por sus territorios ante los tribunales mexicanos tiene décadas, es la defensa de sus lugares sagrados, con un enfoque de derechos humanos, la que les ha permitido fortalecer estas redes y posicionarse como uno de los grupos indígenas mexicanos más visibles. A continuación, de forma breve, analizaremos como han utilizado algunos de estos mecanismos, reivindicando su propia tradición y como, en este proceso, también han ido asumiendo otro tipo de argumentos, históricos o ecológicos, por ejemplo, para discutir dentro de la misma lógica del Estado y los organismos internacionales.

\section{El pacto de Hauxa Manaka}

El territorio del pueblo wixarika no se basa sólo en lo que consideran sus tierras comunales, aspecto que ya es complejo de definir, tanto por la variabilidad de estas, como por la pugna constante con los mestizos. Además, 
se caracteriza por toda una geografía sagrada, a veces situada dentro de los territorios comunales, pero también en lejanos puntos a los que se llega a través del peregrinar. Son varios los autores que han subrayado la importancia del huichol como peregrino. Jáuregui (2008: 134) lo considera un aspecto esencial, que les otorga un lugar con relación a otros indígenas del Nayar. Este peregrinar les permite asumirse como seres luminosos, aliados y defensores del cristo-sol, en contraposición a sus vecinos los coras, que serían seres oscuros y antagonistas del sol.

Los límites del territorio se definen en términos mitológicos y rituales. Cuatro lugares sagrados marcan las fronteras hacia los cuatro puntos cardinales. Al poniente, en San Blas, la costa de Nayarit, habita Tatei Haramara, «Nuestra Madre el Mar»; en el extremo oriental, en el altiplano de San Luis Potosí se encuentra Wirikuta, lugar donde nació el Sol y donde el héroe cultural Kauyumari se manifiesta como el cactus sagrado (peyote o bikur); al sur, en la laguna de Chapala, Jalisco, habita Tatei Xapawiyeme, «Nuestra Madre el Chalate de la Lluvia»; al norte, en Durango, está Hauxamanaka, «el lugar de la madera flotante», también conocido como el Cerro Gordo. El universo huichol se divide en cuatro regiones, demarcadas por los cuatro puntos señalados. En el centro, se encuentra Teakata, donde habita Tatewari, «Nuestro Abuelo» el Fuego, un patio ritual cerca de Santa Catarina (MEDINA, 2012: 90-91).

La mitología, la tradición propia, y no la historia o las demarcaciones territoriales oficiales, es la fuente que nos describe, por tanto, el espacio huichol, sus límites y sus lugares sagrados. Los territorios comunales son sólo una parte de este espacio y cuatro lugares sagrados (Haramara, Wirikuta, Xapawiyeme y Hauxamanaka) son los límites de este universo wixarika. No obstante, los caminos que llevan a estos puntos son incontables. Cada comunidad y, a veces, cada familia, puede llegar por un camino diferente, lleno de pequeños lugares sagrados, solo visibles a los ojos experimentados de los peregrinos. Esta variabilidad, que eleva la riqueza del camino, es uno de los quebraderos de cabeza de las autoridades mexicanas para tratar de registrar el espacio sagrado y protegerlo. De igual forma, presenta importantes paradojas con el problema de la salvaguardia de los espacios, la concepción de territorio y sus usos. Es aquí donde proponemos que un concepto abierto de patrimonio, basado en los derechos humanos, y en el reconocimiento de los pueblos, pudiera servir para dar seguridad a los distintos grupos que habitan y ocupan los territorios.

Y es que dentro de estos límites del universo sagrado atraviesan estados, tierras ejidales, propiedades privadas o incluso poblados. La preocupación por sus lugares sagrados es, sin duda, un elemento que ha permitido a los wixaritari unirse hacia el exterior, y proyectarse de una forma unitaria en torno a un objetivo común.

De entre todos los lugares sagrados, Wirikuta, es el límite del poniente de su universo sagrado, y lugar donde nace el sol según la cosmogonía wixarika. Wirikuta tiene una gran presencia mediática, centrada en el peyote o bikuri, pequeño cactus sagrado que se recolecta en este lugar del desierto potosino. El interés por este cactus y su papel en la cosmogonía huichola ha dado lugar a numerosos textos, tanto científicos como ensayísticos que en buena parte han contribuido a despertar en el público una gran curiosidad por la cultura wixarika (SÁNCHEZ DOMÍNGUEZ-GUILATE, 2016).

Desde los años 90, el turismo se fue incrementando notablemente en la zona de Real de Catorce, el más renombrado de los pueblos de la zona de Wirikuta. Este auge de visitantes llevó a los wixaritari a manifestar su preocupación por el estado de conservación de Wirikuta, en concreto por el papel del turismo en el saqueo del peyote. En los primeros años del siglo XXI, la entrada de Real de Catorce en el programa de Pueblos Mágicos, así como el auge de los movimientos contraculturales New Age, continúo incrementando la llegada de turistas. Además, otros lugares sagrados también se vieron amenazados. Así, desde las autoridades wixarikas comenzó 
a consolidarse una estrategia para defender dichos sitios de forma conjunta, de acuerdo con la constitución mexicana y al marco jurídico internacional. En el año 2008 se llegó a un pacto con el estado que se plasmó el 28 de abril 2008 en el documento de «Huauxa Manaka para la preservación y desarrollo de la cultura wirarika», donde el presidente mexicano Felipe Calderón y cinco gobernadores (San Luis Potosí, Zacatecas, Nayarit, Jalisco y Durango) se comprometían a respetar y proteger los sitios sagrados. Por parte de los huicholes rubricó este pacto el presidente de la Unión Wixarika de Centros Ceremoniales de Jalisco, Durango y Nayarit, A.C.

En este pacto, los wixaritari apelan a su tradición, especialmente a su mitología, para la defensa de sus territorios, y define cuáles son los sitios sagrados, señalando su situación y su significado en la cultura wixarika. A continuación, seleccionamos algunos párrafos de este texto (Gobierno del estado de Nayarit, 2008: 1)

\footnotetext{
"Cinco son los Lugares Sagrados, que marcan los confines del mundo de la cosmovisión Wixárika, mismos que corresponden en su orientación con los puntos cardinales.

1. Poniente: Tatei Haramara, es la madre del maíz de los cincos colores, y la puerta sagrada de entrada al quinto mundo, representada por las dos piedras blancas Tatei Waxieve y Tatei Cuca Wima, que se levantan en el océano Pacifico frente a la Isla del Rey, en el puerto de San Blas, Nayarit; aqui es donde el sol tiene que luchar fuertemente al ocultarse, para renacer cada día allá por Wirikuta, por donde transitaron los ancestros; superficie actual protegida 6 hectáreas;

2. Centro: Tee'kata, lugar del fuego primigenio, donde nació el sol, ubicado en el corazón del territorio Wixárika, en la Comunidad Indigena de Santa Catarina Cuexcomatitlán - Tuapurte, en el municipio de Mezquitic, Jalisco; superficie actual salvaguardada 100 hectáreas;

3. Sur: Xapawiyemeta, lugar donde tocó tierra Watakame el enviado de la madre del universo Takutsi Naakawe, después del diluvio, ubicado en la Isla de los Alacranes, del Lago de Chapala, en el municipio de Chapala, Jalisco; superficie actual reducida a 377 m2; 4. Norte: Hauxamanaka, lugar donde quedó él varado, donde la canoa de Watakame dejó su varado (restos de la canoa y de lo que arrastró el diluvio) ubicado en la parte alta del cerro Gordo o Jaitsi Kipurita, en la comunidad O'dam de San Bernardino Milpillas Chico, municipio de Pueblo Nuevo, Durango; superficie actual protegida 60.75 hectáreas;

5. Oriente: Wirikuta, por donde se levanta el sol, ubicado en el semidesierto de San Luis Potosi, en los municipios de Catorce, Charcas, Matehuala, Villa de Guadalupe, Villa de la Pazy Villa de Ramos en San Luis Potosí. Superficie actual protegida 140,212 hectáreas.»
}

Una vez que han especificado los lugares sagrados, solicitan que el pueblo wixarika sea consultado sobre los mismos y que no se tomen decisiones relevantes sin contar con ellos, tal y como se indican en las legislaciones nacionales e internacionales. En el texto destaca la preocupación que les despierta «el Plan de Manejo del Área Natural de Wirikuta, en la que se identificaron una serie de problemas que ponen en peligro a los lugares sagrados y con ello a la cultura Wixárika» (Gobierno del estado de Nayarit, 2008: 2). El pacto solicita a los gobernadores de los cinco estados representados los siguientes compromisos:

1. Proteger y preservar la continuidad histórica de los lugares sagrados y rutas de peregrinación, mencionando «de manera especial la que se emprende para ir a Wirikuta» (Gobierno del estado de Nayarit, 2008: 3).

2. Evitar el uso de los elementos culturales huicholes «para fines contrarios al ceremonial y tradición del Pueblo Wixárika, salvo los casos que bajo estricto consenso hayan sido previamente acordados» (Gobierno del estado de Nayarit, 2008: 3).

3. Establecer un programa de trabajo basado en «lo establecido en el Plan de Manejo del Sitio Sagrado Natural de Wirikuta» (Gobierno del estado de Nayarit, 2008: 4). 
El primer compromiso, es el que incluye acciones más concretas. Se propone analizar y actualizar las normativas estatales para que protejan y salvaguarden los lugares sagrados. Igualmente, se solicita medidas de difusión y promoción de estos lugares. Por último, se solicita «fomentar espacios para el análisis y la concertación de los grupos sociales con la participación de las instancias gubernamentales para que:

I. Los representantes del Pueblo Wixárika y los representantes de los sectores de la población que se encuentran ubicados en los sitios que cruzan las rutas de peregrinación a los lugares sagrados y los asentados en el entorno de los basados en la conciencia y buena voluntad de las partes interesadas en la preservación, reconocimiento, respeto y continuidad histórica de los lugares sagrados y desarrollo de la cultura wixarika.

Y tomando como referencia los preceptos establecidos en el Artículo $2^{\circ}$ apartado A, fracciones VII, VIII y IX de la Constitución Política de los Estados Unidos Mexicanos, las Constituciones Políticas de los Estados, el Convenio 169 de la OIT, La Declaración de las Naciones Unidas sobre los Derecho de los Pueblos Indígenas y las Leyes propios lugares sagrados, estén en concisiones de definir y poner en marcha las acciones que permitan dar continuidad a sus tradiciones y costumbres.

II. Las dependencias y entidades de la Administración Pública en el marco de su competencia realicen acciones para la protección y salvaguardar de los sitios sagrados del Pueblo Wixárika.

III. Facilitar el libre tránsito de los Peregrinos Wixaritari con los elementos propios de su cultura por las rutas de peregrinación y actividades propias de su tradición cultural.

IV. Las autoridades cuenten con información básica del Pueblo Wixárika

(GOBIERNO DEL ESTADO DE NAYARIT, 2008: 4).

El Pacto de Hauxa Manaka, es un interesante documento donde el pueblo huichol aparece como un sujeto político único y donde se reconoce su tradición como fuente de derecho. Cuando hablo de «sujeto político único» me refiero a que pareciera que dicho pacto ha sido validado de alguna forma con todos sus integrantes. Sin embargo, el firmante era Hermenegildo Carrillo, presidente en aquellos momentos de «POR LA UNIÓN WIXÁRIKA DE CENTROS CEREMONIALES DE JALISCO, DURANGO Y NAYARIT, A.C.) (Gobierno del estado de Nayarit, 2008). Aquí radica la primera de las contradicciones a la hora de hacer válidos esos acuerdos. El reconocimiento de esta asociación, que es una institución que representa sólo a quienes han querido formar parte de ella, simplificó a los gobiernos la tarea de hacer una consulta real entre la población, o identificar a las autoridades que mejor representaran la enorme diversidad del pueblo wixarika.

Es muy habitual que los gobiernos adopten estos atajos y busquen instituciones como la aquí señalada, lo que complica que los acuerdos sean adoptados por todos, ya que no tienen porqué sentirse representados por ellos. A pesar de que las leyes señalan la necesidad de que las consultas sean informadas y representativas, de esta forma es más fácil encontrar interlocutores que puedan validar sus intereses.

En este caso, esta Organización de la Sociedad Civil, figura legal que en México aglutina las ONGs, tradicionalmente ha ido asumiendo la representación del pueblo wixarika ante autoridades externas al mismo. En el contexto de esta controversia de Wirikuta, se funda en abril de 2010 el Consejo Regional Wixarika en Defensa de Wirikuta, que no estaba de acuerdo en muchas ocasiones en cómo la Unión de Centros Ceremo- 
niales gestionaba esta representación. Ninguna de estas instituciones, en términos de normatividad internacional, debería poder ratificar en solitario pactos en nombre del todo el pueblo wixarika. Basta observar, por ejemplo, cómo las mujeres tienen una representación mínima en dichas instituciones.

El pacto se dio por tanto entre estos cinco gobernadores y el presidente de México, por un lado, y el presidente de esta asociación civil, a quien dichas autoridades mexicanas deciden reconocer como el representante de todo el pueblo wixarika. Unos meses antes, en el estado de San Luis Potosí, donde se encuentra el territorio sagrado de Wirikuta, se había emprendido un proyecto de protección del área, declarada patrimonio por el gobierno del estado de San Luis Potosí y publicado como «Plan de Manejo del Sitio Sagrado Wirikuta», coordinado por el Dr. Pedro Medellín Milán, director de la Agenda Ambiental de San Luis Potosí. Según dicho documento, se llevó a cabo una consulta con miembros del pueblo huichol centrado en tres jornadas, y que en total incluyó a 1530 personas. No obstante, la metodología señala lo limitado de la misma, ya que se centró en pocas comunidades y nunca fue ratificado. De nuevo apareció El Plan de Manejo, si bien contemplaba aspectos culturales, se centraba especialmente en la defensa ecológica del lugar.

Este plan, además, se basaba en una zonificación de Wirikuta, con la intención de que se pudieran llevar a cabo distintas actividades económicas en áreas del altiplano, recogiendo las inquietudes de los habitantes de la zona (MEDELLÍN, 2008).

\section{Wirikuta: entre huicholes, neorrurales, activistas y turistas}

Junto a estas estrategias, surge el interés de posicionar Wirikuta para su reconocimiento internacional a través del programa de Patrimonio Mundial de la UNESCO. Esta decisión también siguió un polémico camino. Si bien el expediente está dentro de la «Lista Indicativa» de México, es decir, de aquellos con posibilidades de ser presentados ante la UNESCO, ha sido muy cuestionada su designación dentro de los mismos wixaritari. Especialmente a raíz de una iniciativa para que la Ruta de Wirikuta fuera reconocida en la Lista de Patrimonio Inmaterial de la UNESCO. La desarticulación entre las autoridades políticas, los wixaritari y otros actores ha impedido su designación. Pero también habría que reflexionar sobre la pertinencia de dicho expediente y las consecuencias que podría tener para el sitio sagrado, al exponerse aun más como una meca turística.

El caso de Huauxa Manaka es relevante porque las principales autoridades federales y estatales (gobernadores, presidente) reconocen a los wixaritari como una unidad política, aunque, como hemos visto, sin suficiente representatividad, de acuerdo con los cánones internacionales. Pero también porque se prioriza la importancia simbólica y mítica de los lugares, por encima de otras consideraciones de tipo ecológico, a través del propio relato wixarika: no se da una justificación ambientalista o histórica, sino de respeto a un espacio sagrado mediante su propio relato, aunque con ciertas limitantes (por ejemplo, la definición de los lugares en hectáreas concretas). El mantenimiento de las rutas y de los lugares sagrados se asocia con la supervivencia misma de los wixaritari. En este caso, apelan a los derechos indígenas reconocidos en legislaciones nacionales e internacionales para recordar que es imprescindible consultarles sobre el uso de las tierras. A través de este documento, el estado reconoce esta parte del patrimonio de los huicholes, así como la necesidad de proteger su uso tradicional.

Una vez más, afrontamos las limitaciones de las leyes actuales y del paradigma multicultural a la hora de llevar a cabo dicho pacto: la propia concepción jurídica y política del estado mexicano hizo que sólo se quedara en buenas intenciones, el simbolismo y la solemnidad. Pronto fue violentado por el gobierno federal. El 4 de septiembre de 2009, los derechos de las 22 concesiones pertenecientes a la minera Norbec fueron compradas por una trasnacional aún mayor: First Majestic Silver Corp, una compañía canadiense con importantes intereses 
en México. En total, esta minera dispone de 35 concesiones en la zona, pero 22 se encuentran dentro de las 140,000 has. protegidas por el gobierno del estado de San Luis Potosí como Área Natural Protegida Sitio Sagrado Natural Wirikuta. Posteriormente, en diciembre de 2011, otra compañía minera canadiense, Revolution Resources (actualmente IDM Mining), anuncia su propósito de poner en marcha el Proyecto Universo, con 40 concesiones, algunas de las cuales están ubicadas dentro del Sitio Sagrado. Ambas compañías, de origen canadiense, cuentan con filiales mexicanas que les permiten, de acuerdo con la ley, la explotación minera.

Al otorgar estas concesiones, se rompe unilateralmente por parte del gobierno el Pacto de Hauxa Manaka, lo que desencadena una reacción tanto del pueblo wixarika, como de su entorno, constituido esencialmente por asociaciones civiles, activistas y admiradores, así como científicos sociales, especialmente antropólogos. Se conforma así una controversia, es decir, un proceso donde una serie de actores despliegan toda una gama de discursos, acciones y apropiaciones (LATOUR, 2008 [2005]). Wirikuta es un espacio compartido por numerosos grupos e individuos, un patrimonio social donde confluyen distintas tradiciones y concepciones del mundo.

Si bien la peregrinación de los wixaritari a Wirikuta se presume muy antigua, no disponemos de documentación histórica sobre la misma hasta finales del siglo XVIII. Pero es a finales de los años 60, en pleno auge de los movimientos contraculturales occidentales, que experimentaban con distintas sustancias psicotrópicas, cuando comienza a tener una repercusión internacional. Hasta entonces, los huicholes y los catorceños estaban acostumbrados a compartir un espacio físico que, sin embargo, como en una película de ciencia ficción parecía tener dos realidades paralelas, y contaban incluso con nombres diferenciados: Wirikuta para los wixaritari y las tierras pertenecientes a distintos municipios, para los habitantes de la zona. Los catorceños habitaban el lugar y vivían de él. Los huicholes peregrinaban en pequeños grupos, cortaban sus peyotes y se regresaba a su lugar de origen. A pesar de compartir un espacio, sus actividades casi no se encontraban y durante décadas se ignoraban unos a otros, sin que haya quedado constancia de conflictos entre ellos. Un caballerango de Real de Catorce, en el año 2013, en medio de la controversia, comentaba a un peregrino wixarika: «mi papá tenía un ranchito hace ya muchos años, y ustedes siempre paraban allí a beber agua. Mi papá siempre les dejaba quedarse...». ${ }^{2}$ Los huicholes realizaban sus rituales y se regresaban a sus tierras. No dejaban dinero en el pueblo. Casi no se relacionaban con la gente de allí. Eran vistos por ellos como algo anecdótico, de paso, peregrinos extraños con los que no se mezclaban, salvo cuando pasaban a dejar ofrendas a San Francisco, el patrono local.

Sin embargo, esta coexistencia pacífica, aunque de espaldas unos a otros, se rompió poco a poco, cuando Wirikuta, en interés de mestizos vinculados a la contracultura, empieza a ejercer de vínculo entre ambas realidades. Así, huicholes y locales tienen que mirarse de frente por primera vez. Esta situación se agudiza en los años 90, con la propuesta alternativa de desarrollo económico en la zona, a través del turismo. El pueblo de Real de Catorce, con bellos edificios abandonados, se posicionó como la capital mestiza de este espacio. Este auge turístico está impulsado por grupos de neorrurales (NOGUÉ I FONT, 1988), Se trata de personas procedentes de las clases medias y medias-altas urbanas, que abandonan la ciudad en busca de un mayor contacto con la naturaleza y un estilo de vida más tranquilo. La idealización de la vida en el campo, por oposición a la vida en la ciudad, está en el germen de este movimiento. Las actividades a las que se dedican pueden ser muy variadas: producción de artesanías, agricultura o servicios, generalmente enfocados al turismo (NOGUÉ I FONT, 1988: 145). No obstante, en muchos casos, si bien se abandona la ciudad, se procuran servicios propios

${ }^{2}$ Comunicación personal, Cerro del Quemado, Real de Catorce. Mayo de 2013. 
de la misma (como internet, escuelas privadas, productos de otras partes del mundo, etc.). Estos grupos, también adoptan patrimonios de otras comunidades, a veces abandonados o en estado de decadencia, para refuncionalizarlos («rescatarlos», dirían ellos); pero también se apropian de patrimonios con notable vigor y vigencia. En algunos casos, dan nueva vida a los pueblos, pero, a veces, esto implica también un choque con la comunidad original, que al ver revalorizado su patrimonio se siente amenazado por la presencia de estos foráneos. Esto, por ejemplo, sucede con frecuencia en los «pueblos mágicos» mexicanos, un programa gubernamental que promueve la reconversión turística de ciertos pueblos, y que ha tenido un notable éxito. Así sucedió en la zona de Wirikuta, donde el poblado de Real de Catorce pasó a ser considerado «Pueblo Mágico» desde el año 2001. Los neorrurales se convirtieron en una amenaza para los propios wixararitari, que veían con recelo la venta de sus tradiciones y la explotación del peyote. Sin embargo, en este primer momento, para los locales, supuso una posibilidad de revitalizar sus pueblos.

Con el fin de crear atractivos, los neorrurales que se dedican al turismo, comienzan a fomentar esta relación y dan un papel protagonista al huichol estereotipado, al que presentan como parte de la localidad. Las relaciones ya no son más entre los mestizos, como un grupo homogéneo, y los indígenas. Sino que, entre los mestizos hay muchos que se identifican más con el indígena que con los ejidatarios locales. Provenientes de una cultura cosmopolita, muchos de estos neorrurales se han acercado a espiritualidades New Age, mientras que defienden posturas políticas generalistas, como el ecologismo y los derechos humanos, a la vez que idealizan a los wixaritari, tomando aspectos de su cultura de forma descontextualizada. En este sentido, es importante destacar el papel del peyote, cuya recolección es el objetivo de la peregrinación wixarika y, al mismo tiempo, es el gran atractivo turístico de la zona, a pesar de que es ilegal recolectarlo y/o consumirlo para todo aquel que no es indígena.

El movimiento neorrural en Wirikuta fue ascendiendo en número y en importancia desde el 2001. Nuevas personas llegan al pueblo y adquieren edificios, adaptándolos para convertirlos en hoteles y restaurantes, donde los artilugios propios de la minería se convierten en adornos. Estas personas tienden a organizarse en asociaciones civiles, o participar en la política tradicional, a la vez que disponen de pequeños negocios locales enfocados hacia el turismo. Otros prefieren instalarse en la parte baja, en el desierto donde se recolecta el peyote. Cuando los turistas llegan a la zona buscando una experiencia mística a través del consumo del peyote o simplemente «un viaje» divertido. Algunos, en lugar de llegar al poblado de Real de Catorce, se sitúan en la parte baja del desierto, donde se recolecta la planta y acampan en el desierto, preferiblemente en propiedades privadas o ejidales donde se sienten más seguros y es más difícil que la policía pueda detenerlos.

Los que llegan al Real pueden tomar las viejas camionetas «Willis» que los llevan por la carretera hasta Estación Catorce. Y de ahí, al desierto por unas horas para adquirir la experiencia psicodélica. Además de las personas que llegan directamente a Catorce, hay quienes contactan a operadores turísticos desde la Ciudad de México o San Luis Potosí. Estos operadores adquieren «paquetes» con proveedores locales que proporcionan alojamiento, alimento y, en algunos casos, «guías espirituales» para tomar el peyote. Al ser ilegal, tanto cortarlo como su consumo para aquellos que no son huicholes, los «peyotours», como se conocen estos viajes de forma informal, no son vendidos como tales por los operadores turísticos o guías locales. Simplemente te trasladan a un lugar donde se puede acceder al peyote y dejan que las personas tomen la decisión sobre si quieren buscarlo, cortarlo y consumirlo. En algunos casos, trasladan a los turistas a propiedades particulares donde pueden acceder al peyote, lo que da al foráneo una sensación extra de seguridad. No es difícil encontrar turistas que relatan estas experiencias, tanto en persona como a través de blogs y páginas de internet. Esto se debe a que, a pesar 
de la ilegalidad de la actividad, de alguna forma, está tolerada e incluso se promociona. Contratando estos servicios, estos guías permiten a sus visitantes trasgredir la norma con cierta confianza y, medianamente, estar seguros de que no serán extorsionados por las autoridades federales o estatales. Asimismo, se tiene la certeza de contar con compañía que comparte los mismos intereses, elemento social de vital importancia durante el «viaje».

Además de este tipo de visitas, hay otros que contemplan experiencias más integrales, guiados por personajes que conocen la zona y que venden además una guía espiritual para el viaje. Por supuesto, también hay huicholes que se prestan a estos servicios a cambio de dinero. Algunos de ellos etiquetan su producto como «La ceremonia», donde se ofrece una especie de rito de curación espiritual.

Esta exposición del peyote como un elemento de atracción turística, ha sido parte de un proceso complejo. Desde la literatura, el arte y el ensayo se ha ido destacando este aspecto de la cultura wixarika, muchas veces de forma descontextualizada (SÁNCHEZ DOMÍNGUEZ-GUILARTE, 2016). Podríamos incluso observar que los propios wixaritari llevan a cabo visitas más habituales a Wirikuta, no siempre en el marco de una peregrinación, y que extraen cada vez más peyote. La refuncionalización de esta planta sagrada, por tanto, no ha sido solo hacia el exterior, sino también hacia el interior.

En el momento de la firma de Hauxa Manaka, los wixaritari consideraban que este modelo de explotación turística es el principal riesgo para su costumbre. Pero una vez que se concesionan las minas, el panorama se reconfigura y estos los grupos de neorrurales, que tampoco quieren este modelo de explotación, ya que podría afectar al turismo al poner en riesgo el paisaje y recursos fundamentales como el agua, se convierten en potenciales aliados. Mientras que la población local, ejidatarios y dueños de tierras, en general, ven en las mineras la posibilidad de acceder a trabajo o ingresos económicos, que el modelo turístico, controlado por foráneos, no les había ofrecido finalmente.

Así, esta controversia patrimonial sobre Wirikuta, que se había activado con la llegada de los grupos neorrurales en los años 90, toma un nuevo rumbo ante la actuación de las empresas mineras y el rechazo que provoca dicho modelo entre wixaritari y neorrurales, lo que lleva a formalizar esta alianza en el Frente de Defensa de Wirikuta. Si antes la discusión se daba en torno a la convivencia entre la propuesta turística y los usos tradicionales huicholes, focalizada en el peyote, ahora la controversia en torno al peyote se unifica bajo El Frente y se abre una nueva: entre aquellos que ven Wirikuta como un patrimonio natural e histórico y aquellos que quieren hacer uso de los recursos mineros que alberga, patrimonio de la nación mexicana. La heterogeneidad del primer grupo pasa a un segundo plano ante el peligro que representan las minas; mientras que el segundo grupo, encuentra un modelo alternativo al turístico, donde no se habían sentido incluidos.

La propuesta de reabrir la minería fue vista con buenos ojos por muchos de los habitantes de Real de Catorce y los municipios vecinos. Es importante señalar que esta región solamente ha conocido la bonanza gracias a esta actividad. Se sienten orgullosos de ser hijos de mineros, donde reconocen la dureza del trabajo y la valentía de aquellos que allí vivieron. Mitos, leyendas e historia surgen de las entrañas de la tierra, y la plata sigue siendo el futuro más próspero que ellos perciben, basados en su experiencia y su historia. Así ha sido desde el siglo XVIII: épocas de crisis se alternan con periodos de bonanza auspiciados por la explotación minera. Su patrimonio más valorado, por tanto, es la minería y todo lo que se ha derivado de ella. Los comerciantes locales consideran que la mina podría atraer clientes cotidianos para ellos y que en muchas familias el hombre podría acceder a un trabajo estable. No se engañan acerca de la dureza del trabajo, de lo limitado del mismo. 
También dejan claro que saben que se trata de unos años solamente. Este sector considera que la mina puede cumplir con sus promesas en el cuidado del agua, limitando la contaminación de la zona. Esta gente quiere que se instale la mina, ya que, aunque no llegarán a conseguir empleos, la derrama económica para los pequeños comerciantes podría ser importante. Una comerciante local insistía en que ellos viven de vender y que mientras funcionó el comercio la gente no quería ir a trabajar en la mina. Pero la situación actual es especialmente dramática. Según sus propios relatos, mucha gente que vive en ranchos tiene que hacer tres o cuatro horas diarias de camino para poder vender algunas hierbas o productos realizados en su hogar como gorditas o quesos, para poder obtener algo de dinero que les permita comprar arroz o frijoles, «ya que en las casas no hay que comer». ${ }^{3}$

Ante la reapertura de las minas, los neorrurales contactaron con las distintas comunidades indígenas a las que informaron del riesgo que supone para Wirikuta y el peyote la extracción minera. Así, se empezó a conformar una defensa conjunta donde la controversia en torno al peyote se unifica ante el riesgo mayor que suponen las minas, si bien no se resuelve. Estos sectores se unen en el Frente en Defensa de Wirikuta, «Tamatsima Wahaa», «El Frente» de aquí en adelante. Según su página web ${ }^{4}$ es un colectivo formado por representantes de algunas comunidades wixaritari (San Sebastián Teponahuaxtlán y su anexo Tuxpan y Santa Catarina Cuexcomatitlán, ambos en Jalisco y Bancos de San Hipólito, Durango) y numerosas organizaciones: Unión Wixárika de Centros Ceremoniales de Jalisco, Durango y Nayarit A.C., Centro Mexicano de Derecho Ambiental (CEMDA), Masacalli, autoridades del Ejido Las Margaritas, Pueblo Mágico de Catorce A.C., Frente Amplio Opositor (FAO), Ameyaltonal, Nierika, Centro de Investigación Wixárika, Organi-K, La Tierra Respira, Caravana Universitaria Ricardo Zavala, Playeras Con Causa, Consejo de Visiones y la Iglesia Nativa Americana.

Estas asociaciones estaban coordinadas por la Asociación Jalisciense de Apoyo a Grupos Indígenas (AJAGI). En el año 2015 ellos tenían «las facultades de interlocutores autorizados por las mismas autoridades wixaritari para coordinar la defensa de la zona sagrada de Wirikuta». En su página de Internet señalaban:

\begin{abstract}
«Las autoridades tradicionales, civiles y agrarias de las comunidades Wixaritaris de Jalisco, Nayarit y Durango han formalmente nombrado el Frente en Defensa de Wirikuta. AJAGI fue nombrado por las Autoridades Wixaritari en septiembre de 2010 para coordinar la defensa de Wirikuta. Desde entonces, varias organizaciones en México se han unido para formar el Frente en Defensa de Wirikuta Tamatsima Wahaa (el agua de nuestro hermano mayor). AJAGI tiene las facultades de interlocutores autorizados por las mismas autoridades Wixaritari para coordinar la defensa de la zona sagrada de Wirikuta.

Asimismo el Frente en Defensa de Wirikuta es reconocido como único espacio de coordinación con las comunidades Wixaritari, en las gestiones juridicas, administrativas y estrategia políticas, y en general en todos los ámbitos en que sean afectados y violentados en sus derechos individuales y colectivos como pueblo indigena Wixaritari y en defensa de los sitios sagrados de la Zona de WIRIKUTA (Area Natural Protegida) ubicada en los municipios de Real de Catorce, Villa de Ramos, Charcas, Matehuala, Villa de Guadalupe, Villa de Paz entre otros del Estado de San Luis Potosí, México. ${ }^{\circ}$ "
\end{abstract}

Este Frente realizó una ardua labor de difusión del conflicto, atrayendo figuras públicas y realizando fuertes movilizaciones «con el propósito de diseñar y facilitar estrategias económicas alternativas a la actividad minera para la región». El grupo pro-minas, por su parte, estaba conformado por ejidatarios y otros pobladores locales que se apoyan en las empresas mineras y los gobiernos municipales, principalmente para solicitar la apertura de los pozos. Mientras este grupo es bastante homogéneo, en el caso del Frente observamos una gran heterogeneidad de intereses y de grupos, algunos de ellos en conflicto antes de que estallará el problema de las minas.

\footnotetext{
${ }^{3}$ Comunicación personal. Real de Catorce. Mayo de 2013.

${ }^{4}$ En http://www.frenteendefensadewirikuta.org. Consultada: 16 de mayo de 2015.

${ }^{5}$ En http://www.frenteendefensadewirikuta.org. Consultado: 10 de septiembre de 2013.
} 
Cabe subrayar que no se han resuelto ninguno de los problemas que preocupaban a los huicholes con relación a los usos del peyote y a las garantías para realizar su peregrinación. Se procedió, por tanto, a cerrar una controversia sin estabilizarla, realizando una unificación de los colectivos demasiado pronto, urgida por la necesidad de frenar la explotación minera. Bajo el denominador común de este Frente se situaron numerosas asociaciones y personas, así como autoridades indígenas y wixaritari particulares que tienen distintas visiones de lo que debe ser Wirikuta. El discurso del Frente se funda tanto en la ecología como en la tradición indígena, así como en los derechos humanos.

Ahora bien, estos elementos se combinan priorizando unos sobre otros, o incluso reinterpretándolos. Este sería el caso de los newagers participantes que a pesar de compartir una serie de elementos articuladores con los huicholes los reinterpretan bajo su propia espiritualidad, de forma que sólo superficialmente comparten estos objetos y rituales. También había profesionales de los medios de comunicación, varios músicos de grupos reconocidos -como Café Tacuba, Santa Sabina o La Maldita Vecindad-e incluso se grabó un video junto con el grupo huichol El Venado Azul, interpretando la canción «Wirikuta no se vende» que se convirtió rápidamente en un éxito. También se produjeron exposiciones inspiradas en esta defensa, conciertos masivos y varios documentales.

La creatividad, la riqueza de las expresiones culturales y artísticas y el apoyo de importantes investigadores otorgaron amplia difusión a este movimiento que, a su vez se vio favorecido por la alta valoración del arte huichol y la profundidad espiritual que proyectan muchas de sus tradiciones. Así, trascendió la defensa de los derechos indígenas y se incorporaron a este movimiento opositores al modelo económico y social actual o personas que consideran que Wirikuta es un patrimonio mexicano. Es pues, un grupo muy amplio, con intereses diversos los que se han sentido identificados por este problema: están aquellos que se movilizan por motivos espirituales, por motivos económicos (como los neorrurales) o políticos.

En algunos casos, hay quienes tienen los tres tipos de intereses, como pueden ser algunos miembros de OSC. Además, los académicos se han posicionado mayoritariamente en favor del pueblo wixarika. En este último caso, se puede achacar a los investigadores haber ignorado sistemáticamente los intereses de los catorceños, como bien señala Alvarado (2015) y sin realizar propuestas que permitan generar vías de diálogo.

El nombre adoptado de «Frente» hace referencia al hecho de que es un grupo heterogéneo que se ha unido por compartir un enemigo común: las mineras. En este sentido, un sector del pueblo huichol ha decidido participar, avalar y legitimar esta estrategia, a pesar de que el diseño de esta y su coordinación han sido delegadas a algunas Organizaciones de la Sociedad Civil (OSC), figura legal mexicana para las Organizaciones No Gubernamentales. Para que la movilización social fuera exitosa, el Frente colocó a los huicholes en el centro de la atención, dándoles el papel protagonista a través de una serie de actividades diseñadas para sus simpatizantes, pero donde se exponían tradiciones indígenas. Los rituales, se modificaban para abrirlos al mestizo, lo que generó tensiones también dentro de los propios wixaritari.

El lenguaje utilizado en sus declaraciones, cartas y discursos es claramente híbrido y procede del entorno de las OSC, aunque siempre estén firmadas por las comunidades huicholas que participan en el Frente. Internet y sus redes sociales juegan un papel muy activo en esta movilización y permitieron una interacción directa con los simpatizantes.

A pesar de que, en términos de visualización del problema, la estrategia que propuso el Frente hizo que más personas se concienciaran sobre Wirikuta, observamos como solo hay un reconocimiento muy superficial por parte del estado mexicano la tradición wixarika. Si en Hauxa Manaka la tradición propia era la base para 
elaborar un pacto de respeto y reconocimiento, en las acciones emprendidas por el frente, tanto de defensa legal como de propuesta de manejo de la zona, que aglutinaban acciones sociales encaminadas al desarrollo económico con una mayor apertura del espacio a mestizos que quisieran disfrutar de la experiencia del peyote, todo ello coordinado por pobladores locales y wixaritari, nos encontramos en una propuesta con una lógica multiculturalista, donde los wixaritari incluso ceden la coordinación del movimiento a otras instituciones.

Sin duda, el ámbito legal no permitió una resolución respetuosa del conflicto, pero tampoco los movimientos sociales que, sobre el papel, estaban buscando proteger Wirikuta.

Si la ruptura del Pacto Hauxa Manaka creó que una situación de desconfianza hacia las autoridades federales, concesionarias de las mineras, difícil de superar. La gestión que hicieron las Organizaciones de la Sociedad Civil (OSC) coordinadoras del Frente de los recursos financieros obtenidos, llevó a la ruptura de este. Así, desde abril de 2015, la defensa volvió a ser coordinada por el Consejo Regional Wixarika por la Defensa de Wirikuta , que decidió dar por finalizada su relación con el Frente, ya que «las organizaciones que gestionaron los proyectos no alcanzaron sus objetivos y no fueron transparentes en su rendición de cuentas». ${ }^{6}$

\section{La controversia patrimonial}

Así, en el caso de Wirikuta, podemos hablar de una controversia patrimonial, donde analizamos el patrimonio en construcción, una controversia abierta e inestable a la que deben ser los propios actores los que ofrezcan una solución. El conflicto que se abre a raíz de las concesiones mineras no afectó solamente a los indígenas. En Wirikuta hay ejidatarios tradicionales, que viven de la explotación agropecuaria, también grupos de neorrurales que tratan de emprender un nuevo estilo de vida alejados de la ciudad, buscando pequeños pueblos donde instalarse y con intereses turísticos, entre otros.

Así, no podemos hablar de un patrimonio unívoco, sino de memorias e historias cruzadas que conviven en el mismo espacio. En este caso, y de forma muy general, los habitantes de la zona, peregrinos y visitantes, se aglutinaron en torno a dos frentes: aquel que defendía que las minas no se abrieran y se eliminaran las concesiones, (que se formalizó en el «Frente para la defensa de Wirikuta) y los que veían la mina como una posibilidad de desarrollo económico. En el caso de los habitantes del desierto potosino, su discurso y legitimidad viene dado por el uso histórico del terreno, y el reconocimiento legal de la posesión de tierra. Pero en el caso de los wixaritari es, sin duda, su propia costumbre la que motiva la defensa de estos territorios.

En torno a finales del año 2015, el Frente se fragmentó, generando todavía más complejidad en este caso. Si bien, de acuerdo con los relatos de las distintas partes y con sus comunicaciones oficiales, la ruptura vino dada por la discrepancia en torno a la gestión de los recursos financieros, la realidad es aglutinaba a sectores con muy distintos intereses. El simple hecho de que los wixaritari estuvieran tutorados por las OSCs mestizas a la hora de decidir sobre los procesos a seguir, o sobre el diseño de las actividades de difusión, iba en contra de la autonomía que ellos mismos reivindicaban a través de sus propias asociaciones.

Más aun, pudimos observar como desde este entorno de organizaciones y neorrurales se animaba a los wixaritari a abrirse a los movimientos contraculturales, a exponer más Wirikuta y a compartir el peyote. Para ello, se fueron consolidando discursos híbridos, donde la ecología, la tradición wixarika y la historia se amalgamaban para justificar los intereses de este Frente. Un proceso por otra parte, muy propio del multiculturalismo, donde se tiende a reconocer aspectos culturales sin cambiar la esencia misma de la estructura legal y política, apropiándose a través de estos rasgos de la naturaleza.

${ }^{6}$ En http://consejoregionalwixarika.org/. Consultado: 4 de julio de 2019 
Estos discursos híbridos se fundamentaban en una pseudohistoria, avalada por reconocimientos sociales o incluso institucionales (a veces falsos o deformados) y los mitos originales de los wixaritari, que se utilizaban para defender aquello que consideraban que les pertenecía. Así, la legitimidad del movimiento que, en el año 2008, en la firma de Hauxa Manaka, radicaba básicamente en la tradición indígena, incorpora desde el año 2010 recursos adicionales que validan sus reclamaciones ante el publico mestizo e internacional: el histórico, el ecológico, el espiritual y, por supuesto, el de la defensa de los derechos humanos. Recursos que le permiten llegar a un público mayor y a la vez les obligan a abrir espacios rituales que tradicionalmente estaban resguardados y eran protegidos antes las miradas curiosas. Si querían el apoyo del mestizo, era necesario abrirse al mestizo.

Estos discursos híbridos pretendían fortalecer dentro de la controversia patrimonial el aspecto de santuario natural y espiritual de Wirikuta, obteniendo mayores apoyos para conseguir sus objetivos. Un ejemplo podría ser el siguiente:

«Sobre la antigüedad de la presencia wixárika en Wirikuta: El pueblo wixárika mantiene vigentes rasgos culturales más antiguos a la domesticación del maíz. Antropólogos han destacado el ritual de la cacería de venado como una sobrevivencia de su pasado nómada. Y el pasado nómada de los buicholes se remonta a más de nueve mil años según los utensilios hallados por arquélogos.

Hay evidencias, por pruebas de radiocarbono 14, del consumo humano del peyote o jícuri desde hace más de cinco mil años. Y hay evidencias por estudios realizados con información genética de varios pueblos indígenas del país de que los wixaritari comparten singularidades genéticas con rarámuris, pápagos, pimas y pames, «lo cual comprueba que los wixaritari tienen una marca característica de las culturas del desierto, hábitat del peyote, uno de los motivos por el que peregrinan año con año a Wirikuta». Se trata de hallargos antropológicos que son acercamientos cientificos que alimentan la hipótesis del carácter milenario de la peregrinación wixárika a Wirikuta, nunca comparable a los tan sólo 200 años en que comenzó la actividad minera en Wirikuta o los cien años de cuando colapsó su auge dejando miseria, contaminación, deforestación y desecación (Chávezy Chávez, 2013).»

Los datos presentados en este artículo están descontextualizados, no mencionan las fuentes y son difíciles de probar, pero están llenas de argumentos que podrían aparentar ser científicos: genéticos, históricos, antropológicos, etc... Este tipo de discursos fueron ampliamente utilizados por los líderes del movimiento como una forma de aportar legitimidad a sus propuestas. A pesar de que los discursos parecen defender la legitimidad de los indígenas a la hora de reivindicar sus derechos sobre su tierra sagrada, el hecho mismo de utilizar argumentos propios de la tradición occidental, lleva a situaciones muy complejas que, incluso, pudieran ser refutadas con otros datos científicos. Los propios wixaritari han incorporado en la defensa de su tierra sagrada el relato histórico y el valor ecológico, (por ejemplo, se refieren a Wirikuta como un «jardín botánico» en un comunicado del Consejo del 22 de agosto de 2015) ${ }^{7}$

Siguiendo la propuesta de Aguilar Ros (2013), consideramos que estos discursos también se apoyan en una serie de elementos articulatorios valorizados globalmente y que permiten enlazar automáticamente con una serie de colectivos contraculturales que los identifican como propios. Por ejemplo, el empleo de ideas como «la madre tierra» o «pachamama», o «la energía como entidad que mueve al mundo», han permitido conectar con personas y grupos cercanos al mundo Nueva Era o a movimientos ecologistas donde se reconoce la naturaleza como un actor. Otros elementos que sirven como articuladores se refieren a los valores que, desde los aliados de los huicholes, se asignan a los pueblos indígenas en general.

Así, se considera que estos pueblos defienden modelos de vida ecológicos y participativos. En este sentido, el indígena aparece como la alteridad altamente valorada donde su forma de vida es un modelo de respeto al medio ambiente. De igual forma, las largas asambleas y las formas de gobierno son consideradas un modelo democrático, a pesar de no contar con las características objetivas para ello.

7 En http://consejoregionalwixarika.org. Consultado: 4 de julio de 2019. 
Todos estos elementos llevan a reestructurar el discurso mítico original y replantearlo para llevarlo al campo del multiculturalismo, donde Wirikuta se presenta como un espacio natural único sobre el que se exponen diferentes valores culturales, ecológicos e históricos. De hecho, Wirikuta cuenta con un expediente dentro de la tentative list de México ante Patrimonio Mundial, como uno de los posibles lugares para ser presentado a formar parte de Patrimonio de la Humanidad.

Esta propuesta, como vía para visibilización y defensa del espacio, fue primero impulsada por algunas asociaciones de la zona, pero posteriormente fue asumida por los propios wixaritari como una reivindicación. Sin embargo, los modelos de Patrimonio Mundial, que se dividen intangible y tangible y, está última clasificación, en natural y cultural, se han mostrado muy limitados a la hora de proteger un espacio tan complejo como un lugar sagrado indígena. De nuevo, observamos las limitaciones del modelo multiculturalista liberal y debemos pensar en utilizar nuevas categorías, que permitan una verdadera salvaguarda y garanticen el mantenimiento del costumbre propio de los pueblos indígenas.

Este caso, nos presenta claramente como el patrimonio actual, y el entramado legal en el que se mueve, que derivan de la tradición positivista, difícilmente pueden contribuir a proteger patrimonios indígenas de enorme complejidad. Si nos atenemos a la propuesta de Descola 2008 [2005], podríamos decir que las diferentes ontologías entre los pueblos llevan a esta incomprensión y que la aceptación del multiculturalismo como ideología solo invita a los pueblos a caminar por el camino de la democracia liberal, con el propósito de que esos patrimonios sean universalizados y, de esa forma, abiertos a quién quiera disfrutar de ellos, normalmente con un propósito mercantilista enfocado en el turismo.

\section{Conclusiones}

Si bien el multiculturalismo se ha convertido en la ideología dominante y al calor de dicha ideología se ha generado un sistema de derecho donde se reconocía la posibilidad de ser diversos culturalmente, la realidad es que en la práctica no generó verdaderas transformaciones que permitieran implementar mecanismos para reconocer al otro, ya que este paradigma necesariamente implica la renuncia a la propia forma de entender el mundo y la relación entre la naturaleza y la cultura. Aunque el discurso multiculturalista ha permitido el reconocimiento de derechos y la revalorización de los pueblos indígenas, las expectativas generadas han llevado a la frustación y el desengaño de muchos de estos pueblos, que continúan viendo como los sucesivos gobiernos ignoran la necesidad de implementar consultas informadas para decidir sobre lo que ellos mismos reconocen como sus patrimonios.

Son muchos los que han criticado al multiculturalismo. Algunos autores señalan que esta ideología es la cara amable del neoliberalismo, pero que no deja de pertenecer a este sistema. Esto implica que «contiene una concepción de qué es la diversidad y cómo debe insertarse en el sistema de dominación [...] está henchido de principio y valores liberales que son su núcleo» (DÍAZ-POLANCO: 54-55). Otros, como ya hemos visto, destacan que pertenece a una ontología naturalista, propia del modelo occidental-liberal, donde se reconoce una naturaleza única y una multiplicidad de culturas (DESCOLA (2008 [2005]) y VIVEIROS DE CASTRO (2013 [2002]).

No podemos dejar de pensar que la historia positivista es una de las bases del modelo liberal occidental, una ciencia que contribuye a justificar a los estados-Nación su existencia, y a sus leyes su preminencia sobre otras tradiciones. Aunque la legislación internacional de reconocimiento de derechos haya abierto otros espacios, finalmente, estas instituciones internacionales también están conformadas por los propios estado-Nación. 
Este corpus legal, creada dentro del paradigma liberal, hace difícil comprender la relación con un espacio donde no deba haber una explotación económica, donde puedan convivir visiones distintas, donde se tenga que gestionar el paso por territorios privados y donde todo ello se justifique en esa tradición propia, en esa concepción diferente del mundo. Es difícil asumir que hay lugares que cambian, hitos naturales que son dioses y que, además, no existe una versión consensuada sobre esto, sino que cada familia, cada comunidad, tiene su propia lectura del paisaje, su propia relación con el mismo.

En el caso de Wirikuta, observamos como aquellos que se consideraban a sí mismos aliados de los wixaritari en favor de Wirikuta, plantearon una propuesta donde se debía «traducir» su propia costumbre para que pudiera encajar en el rompecabezas liberal. Así, se realizan intentos de convertir en historia los mitos, en propiedad privada el desierto o en una propuesta turística un lugar sagrado. Todo esto no deja de ser una propuesta de absorber la otredad, eso si, con mejores formas e intenciones, pero potencialmente igual de destructiva para los wixaritari que la que provenía de las minas. Dentro de los propios wixaritari, hay quienes decidieron asumir esas propuestas y, guiándose demanda creciente de productos turísticos, han ido generando nuevos servicios para los visitantes de Wirikuta, con ceremonias hechas ex profeso para ellos, adoptando la propuesta de explotar comercialmente el espacio, de integrarse en este modelo. Algunos, incluso, buscan la forma de comprar pequeños terrenos en Wirikuta, apropiándose de ese modo de las estrategias occidentales de propiedad y convirtiendo un espacio de todos en propiedad privada. Si bien todos compartían la meta común de que se eliminaran las concesiones mineras, los interesas eran muy diversos.

El costumbre wixarika, con sus mitos y sus rituales, debió haber sido suficiente argumento, igual de poderoso que la historia o cualquier otra ciencia positivista para defender su vinculación con Wirikuta, pero estos aliados, conocedores de la dinámica liberal, optaron por transformar los discursos indígenas en argumentos científicos. Estos parecían ser más poderosos a la hora de defender Wirikura ante las instituciones nacionales mexicanas e internacionales.

El modelo patrimonial actual, se encuentra dentro de esta lógica, donde la historia tiene un peso fundamental y que sirve para justificar el control de los Estado-nación sobre aquellos espacios de espacial relevancia simbólica y/o con un potencial de explotación económica (PRATS, 1997). En la legislación y política actual, el patrimonio biocultural casi siempre es abordado desde una perspectiva de explotación turística, contribuyendo en muchos casos a la folclorización y museificación de las tradiciones. En Wirikuta, la alternativa al modelo de desarrollo impulsado por la minería era un modelo de desarrollo turístico. Así, por ejemplo, son algunos wixaritari y sus aliados quienes, a través de propuestas de apertura para la defensa de su territorio sagrado, decidieron tomar este camino, proponiendo una vía de explotación económica del lugar.

No obstante, considero que hay aspectos muy interesantes de este proceso que pudieran llevarnos a replantear el concepto de patrimonio para que pudiera ser una herramienta en la defensa efectiva de las costumbres de los pueblos del mundo: tanto por la diversidad de los aspectos que reconoce como patrimonio de los pueblos, como por el hecho de que los sujetos que ostentan los patrimonios son colectivos. Podríamos, por tanto, abandonar esa idea de los patrimonios de la humanidad o de la nación, que invisibilizan a los pueblos originarios, y promover un modelo basado en la propia tradición, donde se reconozcan a los pueblos del mundo por su nombre propio.

Por supuesto, antes será necesario definir qué se considera patrimonio de los pueblos, si una cáscara vacía de elementos culturales dispersos, o un elemento profundo donde se reconoce el derecho de los grupos humanos a decidir sobre aquello que consideran suyo: incluyendo aquellos recurso tradicionalmente tan 
valiosos para los Estados (minerales, agua, tierra, entre otros). También es imprescindible analizar la diversidad de los actores que se vinculan a los patrimonios y, como en el caso de Wirikuta, reconocer los espacios compartidos. Y más aun: esto no servirá de nada mientras no existan consultas reales y efectivas, con la diversidad de sujetos que componen los pueblos indígenas, hombres y mujeres, que decidan sobre dichos patrimonios.

Sin duda, el multiculturalismo ha permitido una reflexión global hacia un mayor reconocimiento del otro. Como parte de esa estrategia, la diversificación del patrimonio ha permitido generalizar el concepto etnológico de cultura, y sustituir la visión elitista decimonónica que todavía se mantenía vigente. Ahora, en el contexto político global, hacemos frente a una reacción conservadora, extractiva, blanca y machista que se está dando en muchos países, como en Estados Unidos con el presidente Trump o en Brasil con Bolsonaro, que nos debería llevar a pensar acerca de si la lógica multicultural puede hacer frente a esta agresión a la diversidad, o es hora de plantear un nuevo paradigma que permita superarla.

La crisis ambiental, agudizada por esta reacción conservadora, también debería ponernos a considerar otros modelos. Quizás, propuestas legales inclusivas, compartidas y que no respondan únicamente a la este modelo extractivo que ve la naturaleza como un objeto del que debemos apropiarnos, pudiera ser un buen lugar donde empezar. Y quizás el reconocimiento del derechos de los pueblos a disfrutar de sus patrimonios, sin que esto signifique necesariamente que sean sometidos a una explotacion económica, también pudiera contribuir a ello.

\section{REFERENCIAS BIBLIOGRÁFICAS}

AGUILAR ROS, A. (2013). «Estrategias de resistencia y negociación de los bienes culturales en el chamanismo wixaritari: proceso de articulación». En Variaciones y apropiaciones latinoamericanas del new age. R. de la Torre, C. Gutiérrez Zuñiga y N. Juárez Huet (coords.). México: CIESAS - El Colegio de Jalisco (Publicaciones de la Casa Chata).

ALVARADO, NEYRA P. (2015). «Inclusión / exclusión. El conflicto en la cohabitación de los habitantes de Catorce, San Luis Potosí̀. En 2015 M. Gálvez (coord.). San Luis Potosí: Colegio de San Luis

BARIÈ, CLETUS G. (2003 (2000)). Pueblos indígenas y Derechos constitucionales en América Latina: un panorama. Bolivia: Editorial Abyayala

CONGRESO DE LOS ESTADOS UNIDOS MEXICANOS (2019). Constitución Politica de los Estados Unidos Mexicanos. México: Diario Oficial de la Federación.

CRUZ RUEDA, E. (2014) Derecho indígena: dinámicas jurídicas, construcción del derecho y procesos de disputa. México: Instituto Nacional de Antropología e Historia (Colección Interdisciplina. Serie Logos)

DESCOLA, P. (2003 (2001)). «Más allá de la naturaleza y la cultura» En Antropología de la naturaleza. Ph. Descola. Perú: Instituto Francés de Estudios Andinos, Lluvia Editores.

DÍAZ-POLANCO, H. (2011). «Diez tesis sobre identidad, diversidad y globalización». En Justicia y diversidad en América Latina. Pueblos indígenas ante la globalización. V. Chenaut, M. Gómez, H. Ortiz y M.T. Sierra (coords.). México: Centro de Investigaciones y Estudios Superiores en Antropología Social, Facultad Latinoamericana de Ciencias Sociales, Ecuador (Publicaciones de la Casa Chata).

GOBIERNO DEL ESTADO DE NAYARIT (2008). Pacto de Hauxa Manaka para la Preservación y Desarrollo de la Cultura Wixarika. Tepic: Periódico Oficial del estado de Nayarit.

JAÚREGUI, J. (2008) «La región cultural de Gran Nayar como «campo de estudio etnológico». En Boletín Oficial del Instituto Nacional de Antropología e Historia. 82: 124-150. 
LATOUR, B. (2008) Reensamblar lo social. Una introducción a la teoría del actor-red. Buenos Aires: 2008 (2005).

Medellín Milán, Pedro (coord.) (2008). Plan de Manejo del Sitio Sagrado Natural Wirikuta, Gobierno del estado de San Luis Potosí. San Luis Potosí: Secretaría de Ecología y Gestión Ambiental.

MEDINA MIRANDA, H. M. (2012). Relatos de los caminos ancestrales. Mitología wixarika del sur de Durango, México: M.A. Porrúa - Universidad Autónoma de San Luis Potosí.

NOGUÉ I FONT, (1988). «El fenómeno neorrural». En Agricultura y sociedad 47: 145-175.

OIT (1957). Convenio no. 107 sobre Pueblos Indígenas y Tribales. Ginebra: OIT.

OIT (1989). Convenio no. 169 sobre Pueblos Indígenas y Tribales en Países Independientes. Ginebra: OIT.

ONU (1992). Declaración sobre los Derechos de las Personas pertenecientes a Minorías Nacionales o Étnicas, Religiosas y Lingüísticas. Nueva York: ONU.

ONU (2007). Declaración de los Derechos de los Pueblos Indígenas. Nueva York: ONU.

PRATS, L. (1997) Antropología y Patrimonio. Barcelona: Ariel.

SÁNCHEZ DOMÍNGUEZ-GUILARTE, C. (2015) La controversia Wirikuta: hacia un nuevo modelo de patrimonio (tesis doctoral). Salamanca.

SÁNCHEZ DOMÍNGUEZ-GUILARTE, C. (2016) «Los wixaritari a través de la antropología, la historia y la literatura: la construcción y popularización de un estereotipo». En Fronteiras V.18, N. 32.

UNESCO (1982). Declaración de México de la Conferencia Mundial sobre las Política Culturales. México.

VIVEIROS DE CASTRO, E. (2013 (2002)). «Perspectivismo y multinaturalismo en la América Indígena». En Cosmopoliticas. Perspectivas antropológicas. M. Cañedo Rodríguez (ed.), Madrid: editorial Trotta. 